\title{
Subsidizing education by taxing wage versus subsidizing wage by taxing education: which pro-employment policy matters?
}

\author{
Raies Asma \\ URED, FSEG, University of Sfax (Tunisia) \\ CED -TEAM, University of Parisl Sorbonne, (France)
}

\begin{abstract}
A belief that a better-trained workforce will enhance employability of workers at the individual level and thus reduce unemployment at the agregate level is commonly held. Nevertheless, in spite of massive public resources devoted to the education sector in developing countries, unemployment rates still strongly hit the most educated populations. This article develops a simple and tractable neoclassical model that shows how unemployment and human capital investment are related to each other. It also compares the consequences on employment of two pro-employment policies, namely, subsidizing education by taxing wage versus subsidizing wage by taxing education. The results suggest, contrary to the common belief, a negative relation between employment rate and human capital investment and show that education should be taxed rather than subsidized.
\end{abstract}

Keywords: Unemployment, human capital investment, taxes and subsidies policies

JEL Classifications: H52,I25, I28, J23, J24, J38.

\section{Introduction}

For a long time, most economists are inclined to think that education and training reduce unemployment. In the belief that human capital investment enhances firms' labour demand and productivity, a positive relationship between education and employment has been taken for granted and widely accepted as selfevident in the theoretical economic literature. A strong negative relationship between unemployment and education has been found in a number of studies, pointing out to different mechanism explaining the dynamics (e.g. Mincer, (1994); Spence, (1981); Kettunen, (1994); (Winkelmann, (1996)). Increased education is likely to make the skills of an individual more valuable in production and consequently, for his/her employability prospects. Pissarides (1990), Laing and al. (1995), Burdett and Smith (2002) argued that workers' decision to invest in education and firms' job creation decisions interact positively. The study of Machin and Manning (1999), focusing on the long run unemployment, argued that education is one of the main determinant factor of workers' employability. According to Moen (1999), competition for jobs implies that human capital investment increases the worker's probability of finding a new job. Accordong to Acemoglu (1999), an increase in the proportion of skilled workers leads firms to create more jobs for skilled workers and to decrease the demand for unskilled ones. More recently, Higashi (2002) shows- in a context of equilibrium search model with inter-firms labour mobility- that unemployment rate is low when firm specific human capital is important. This arises because the number of workers who quit their jobs is small. Finally, Brunello and al, (2009) find that increased education raises the efficiency of the matching process as more educated workers are more mobile and have a broader range of search possibilities, thus, decreasing their unemployment probability.

This positive relationship linking education and employment was confirmed by many micro-empirical studies. For example, using UK data, Nickell (1979) concludes that each year of schooling up to 12 years reduces the expected duration of unemployment by over 4 percent, and that the acquisition of qualifications at ordinary levels or above reduces the expected unemployment duration by 12 percent. Mincer (1991) similarly demonstrates shorter duration of unemployment for better educated workers. Devine and Kiefer (1991) show that workers' education increases the exit rate from unemployment and reduces the entry rate to employment. Berman and Machin (2000) who studied 37 countries from all stages of development show a rising demand for highly skilled workers and thus a falling demand for low-qualified labour in middle-income non-OECD countries such as Venezuela, Uruguay, Chile, Columbia, Peru, Guatemala, Malaysia and Republic of Korea. Givord and Maurin (2003) analyze the changes in the risks of involuntary job loss in France between 1982 and 2000. They find that these risks are 2 to 3 times lower for educated workers. Using US data over the period 1981 to 2001, Farber (2004) finds that job losers with higher levels of education have higher post-displacement employment rates and are more likely to be reemployed full-time. Kadzamira (2003) and Pfeifer and Chiunda (2008) find that, in Malawi, graduates are more likely than others to find a job, and that there is excess of demand for skilled labor by the private sector. McIntosh (2008) finds that, on average, across the OECD countries, individuals with only lower secondary education are over two and a half times more lilely to be unemployed than individuals with a tertiary education. Recently, Garrouste, Kozovska and Perez (2010) consider data from the EU-SILC 2005 of individuals aged 20-65, and found that the higher the educational level, 
the lower the probability of falling into long-term unemployment. Finally, using vietnamien longitudinal data over the period 1980-2005, Riddell and Song (2011) find evidence that higher education reduces the incidence of unemployment and significantly increases re-employment rates of the unemployed.

Being convinced by the necessity of increasing per worker human capital, governments in both developing and developed economies have massively invested in the education and training of their labour force populations by devoting increasing resources to the educational sector. As a result, the positive relationship between education and employment argued by micro-empirical studies cited above is not found on the aggregate level. Indeed, while per worker human capital investment has considerably increased over the last two decades in most of these countries, unemployment rates remain still high especially in many developing countries. In addition, while unemployment hits primarily unskilled workers in developed countries, it hinders the most educated populations in the developing countries so that the huge and increasing flows of educated populations in these economies become a growing concern.

The present paper aims at contributing to the recent litterature by re-examining the relationship between education and employment and explaining the persistence of relatively high unemployment rates observed in many countries despite the massive ressources devoted to education. We develop a neoclassical model with Romer (1990)'s variety expansion framework in wich we include employees' human capital. Individuals decide to invest in human capital by maximizing their gain function and firms demand the amount of labour which maximizes their profit. These strategic decisions involve two effects of opposite signs on the labour demand: i) a profit or encouragement effect: human capital investment increases firms' output, which in turn, raises their profit and encourages their demand for labour; ii) a wage or discouragement effect: an increase in the per-worker human capital implies a higher wage and thus discourages firms to demand labour. We show that the negative wage effect outweighs the positive profit one. This result leads, contrary to the common belief, to a negative relationship between employment and education impling that, wage should be subsidized and education taxed rather than subsidized.

Our study is organised as follows. The second section presents the model. It describes the final firms' decision in term of labour demand, the workers' decision in term of human capital investment and finally, the economy's equilibrium. The third section evaluates and compares two pro-employment public policies namely subsidizing education by taxing wage versus subsidizing wage by taxing education. The fourth section concludes.

\section{The Model}

We consider a closed economy which consists of a fixed number of identical active individuals (normalized to unity) and two production sectors: final and intermediate. The final sector comprises a large number of identically and perfectly competitive firms producing a single final consumption good, $Y$, by combining labour and series of different varieties of capital goods purchased from the intermediate producers. The intermediate sector consists of $T$ firms producing capital goods noted by $X$. This sector is monopolistic as each intermediate firm is a licence-holder of the capital good it innovates (or it adopts). From the production side, final firms maximize their profit by fixing the number of workers to hire, noted by $L$ and the quantity of capital goods to purchase given the per worker human capital level.

\section{Individuals' investment in human capital:}

Individuals belonging to the active labour force population are identical in all respects. They are endowed with one unity of labour and they invest the same level of human capital, $h>1$. They decide about their investment in human capital by maximizing their expected labour income in a context of unemployment. We assume that every worker faces the same probability to find a job.

We make here some fundamental hypotheses reflecting either some previous theoretical findings or stylised facts.

- First, investment in human capital entails monetary costs that we note by $\phi(h)=b h$, where $b$ is a positive parameter indicating the per unity cost of human capital.

- Second, being employed, an individual gains a wage, $w(h)$, which increases with his/her human capital, $h$.

We assume that: $w=a h^{\varepsilon}$, where the parameter $\varepsilon(0<\varepsilon<1)$ indicates the "individual" marginal return of human capital and $a(a>0)$ is interpreted as per unity returns of human capital. This specification reflects the decreasing human capital marginal return which has been empirically established, namely in the well known works of Mincer (1974), Psacharopoulos (1994) and Psacharopoulos and Patrinos (2004).

- Third, we assume the absence of any unemployment benefits; an assumption which is especially relevant in the case of developing countries. 
In a context of unemployment $(L<1)$, $L$ stands simultanously for total firms' labour demand, employment rate and the probability to be employed which is the same for all individuals. We can define the following expected surplus function of a risk-neutral individual with job uncertainty:

$$
G=L w(h)+(1-L) \cdot 0-\phi(h)
$$

That is, an individual earns, with probability $L$, a wage that depends on his human capital $h$, while he has to subtract the cost of his investment in education, $\phi(h)$.

Following the hypotheses announced above, the relation (1a) re-writes as:

$$
G=L\left(a h^{\varepsilon}\right)-b h
$$

This individual has to decide about the amount of his human capital investment that maximizes the surplus function (1b) given the employment rate and the educational cost. The human capital supply function of this worker is therefore given by:

$$
h=\left[\frac{\varepsilon a L}{b}\right]^{\frac{1}{1-\varepsilon}}
$$

It comes out that the individual level of human capital investment increases with the probability to get a job (i.e. the employment rate), and with the parameters characterising the return of this investment, $a$ and $\varepsilon$. It decreases with the per unity cost of human capital, $b$.

\section{Final firms' technology:}

For the production technology of a representative final firm $i$ we adopt Romer (1990)'s framework in wich we include employees' human capital. Hereafter, the production technology we assume is a constantreturns to scale Cobb-Douglas function in labour measured in efficient units, and series of capital goods varieties, $X_{j}$, entering additively in the production technology. Specifically, we consider the following production function of a representative final firm $i$ :

$$
Y_{i}=f\left(L_{i}, X_{i j}\right)=A\left(h L_{i}\right)^{\beta} \sum_{j=1}^{T}\left(X_{i j}\right)^{\gamma}
$$

where $A$ is the exogenous technological progress, $T$ the number of intermediate firms, and $\beta+\gamma=1$. The assumption of identical individuals implies that worker's humain capital level is the same for all firms. Setting the price of final output to unity, the program of a final firm reads as:

$$
\max _{L_{i}, X_{i j}} \Pi_{i}=Y_{i}-\left(a h^{\varepsilon}\right) L_{i}-\sum_{j=1}^{T} p^{X_{j}} X_{i j}
$$

where $p^{X_{j}}$ denotes the price of the capital good of variety $j$.

First order conditions imply that the demanded quantities of capital good of type $j$ and labour are such that their marginal products equal their prices. Hence, we obtain:

$$
\begin{gathered}
X_{i j}=\left[\frac{\gamma A}{p^{X_{j}}}\right]^{\frac{1}{1-\gamma}} L_{i} h \\
L_{i}=\frac{\beta Y_{i}}{a h^{\varepsilon}}
\end{gathered}
$$

The price of each capital good variety, $p^{X_{j}}$, is set by the corresponding intermediate firm $j$ holding the licence of innovating (or adopting) that type of equipment. This monopolist sets his price so that his marginal revenue equals marginal cost. That is: 


$$
p^{X_{j}}\left(1-\frac{1}{\left|e_{\left(X_{j} / p\right)}\right|}\right)=C_{m}^{X_{j}}
$$

Where $e_{X_{j} / p}$ and $C_{m}^{X_{j}}$ denote the demand price-elasticity and the marginal cost of producing the capital good of type $j$ (or holding its licence), respectively. Assuming this marginal cost equals unity and using from the demand equation (5a) the fact that $e_{X_{j} / p}=-1 /(1-\gamma)$ for all the intermediate capital goods, we can easily show that each monopolist sets a profit maximizing price of:

$$
p^{X}=p^{X}=1 / \gamma
$$

Substituting this result in equation (5a), we re-write the quantity of capital good of variety $j$ demanded by a representative final firm as follows:

$$
X_{i j}=X_{i}=\left[A \gamma^{2}\right]^{\frac{1}{1-\gamma}} L_{i} h
$$

Hence, each final firm $i$ demands the same quantity of capital good of variety $j$.

It follows that total demand addressed by all final firms for a given variety of intermediate good $j$ writes as:

$$
X_{j}=\sum_{i} X_{i j}=\left[A \gamma^{2}\right]^{\frac{1}{1-\gamma}} L h=X
$$

Parting from equation (5b), the employment rate of the economy is:

$$
L=\frac{\beta Y}{a h^{\varepsilon}}
$$

where $Y$ is aggregate output produced by the final firms which is determined as follows:

$$
Y=A(h L)^{\beta} T X^{\gamma}
$$

By substituting equation (8) into (9), one may express the employment rate as follows:

$$
L=\left(\frac{\beta A T}{a}\right)^{\frac{1}{1-\beta}} h^{\frac{\beta-\varepsilon}{1-\beta}} X
$$

\section{Free-entry equilibrium}

An intermediate firm must incur the fixed entry $\operatorname{cost} \theta$ to become an entrant and join the industry. We assume that potential entrants face the same entry cost, $\theta$, and are as efficient as incumbent firms, having the same marginal cost $C_{m}^{X}=1$ and thus the same price $p^{X}=1 / \gamma$. Intermediate firm's profit writes then:

$$
\pi=X(1-\gamma) / \gamma
$$

In a free-entry equilibrium, $\pi=\theta$. Substituting in (11) gives the following level of $X$ :

$$
X=\frac{\theta \gamma}{1-\gamma}
$$

\section{Equilibrium of the economy:}

The system formed by equations (2), (7b), (10) and (12) describes the economy and shows how endogenous variables mutually interact. By solving this system, we can determine the equilibrium levels of employment rate $L^{*}$, number of intermediate firms, $T^{*}$, human capital investment, $h^{*}$, and purchased capital goods, $X^{*}$ : 


$$
\left\{\begin{array}{l}
X^{*}=\frac{\gamma \theta}{1-\gamma} \\
h^{*}=\Omega^{\frac{1}{(1-\varepsilon)}}\left(\frac{\varepsilon a}{b}\right)^{\frac{1}{(2-\varepsilon)}} \\
L^{*}=\Omega\left(\frac{b}{\varepsilon a}\right)^{\frac{1}{2-\varepsilon}} \\
T^{*}=\Omega^{\frac{(1-\gamma)(1-\varepsilon)-\gamma}{(1-\varepsilon)}} \frac{a}{(1-\gamma) A}\left(\frac{(1-\gamma)}{\gamma C e}\right)^{\gamma}\left(\frac{b}{\varepsilon a}\right)^{\frac{(1-\varepsilon)}{(2-\varepsilon)}}
\end{array}\right.
$$

where $\Omega=\frac{\gamma \theta}{(1-\gamma)}\left(A \gamma^{2}\right)^{\frac{-(1-\varepsilon)}{(1-\gamma)(2-\varepsilon)}}>0$

We deduce from $\left(S^{*}\right)$ that, $L^{*}=\Omega^{\frac{2-\varepsilon}{(1-\varepsilon)}} / h^{*}$.

This last result is crucial in the sense that, contrary to a common belief, complementarities in firms and individuals' strategic decisions result in a negative relationship between employment rate and human capital investment. This arises because these complementarities imply that human capital and firms' labour demand interact mutually. More precisely, three effects of different signs take place.

- The first effect is a profit or encouragement effect of $h$ on $L$. Indeed, according to Eq. (3), human capital investment, $h$, increases firms' output $Y$, raises their profit (Eq. (4)) and encourages their demand for labour (Eq. (10)).

- The second is a wage or discouragement effect of $h$ on $L$ : an increase in $h$ implies, a higher wage since we have: $w=a h^{\varepsilon}$. The labour cost increment lowers firms' profit, which discourages them to demand labour (Eq.(8)).

- The third effect is a positive encouragement effect of $L$ on $h$, as shown in the gain equation (Eq.1b). That is, a higher employment rate $L$ increases individuals' chance to be employed, which, in turn, raises their gain and encourages them to invest in human capital (Eq. (2)).

The nature of the relationship between employment rate and human capital investment depends on the relative importance of these effects. Our model displays a negative relationship between education and employment, which implies that discouragement effect (via wage), outweighs the two encouragement ones. This theoretical result agrees with the observed persistence of unemployment in most of developped and developping countries despite the increased human capital investment and why unemployment hinders the most educated populations.

\section{Analysis Of Pro-Employment Policies}

We examine in this section the consequences of two public policies which should, in principle, enhance employment. The first policy is to subsidize education by taxing wage, the second is to subsidize wage paid by firms by taxing education. The former policy is adopted in many developed and developing countries whereas the latter is not yet adopted anywhere.

\section{The impacts of subsidizing education by taxing wage:}

We assume here that the government subsidizes the education cost paid by individuals at a rate of, $\eta$, so that the latter pay a net cost equals to $(1-\eta) b h$ instead of $b h$. Total subsidies, $\eta b h$, are financed through a proportional tax, $\tau$, levied on the workers' wage. Hence, under this policy regime, the state subsidizes individuals'education, at a cost of paying a tax on their wage. 
This subsidy policy has two opposit effects on human capital, $h$ : i) an encouragement effect stemming from a reduced education cost which increases individuals' gain $G$; and ii) a discouragement effect associated with wage taxation which reduces the individual's expected gain $G$.

Under this policy regime, the government's budget equilibrium implies that total investment in education should be equal to total taxes on labour-income. That is, the following equality should hold at this equilibrium:

Hence,

$$
\tau w L=\eta b h
$$

$$
\tau=\frac{\eta b h}{a h^{\varepsilon} L}
$$

Under this education policy, the expected gain function of a representative worker (equation 1b) becomes now:

$$
G=L\left(a h^{\varepsilon}\right)(1-\tau)-(1-\eta) b h
$$

Substituting (11b) in (12a) gives the same gain function as (1b)

$$
G=L\left(a h^{\varepsilon}\right)-b h
$$

The individual's gain function remains unchanged after this policy. This implies that the negative discouragement effect of tax offsets the positive encouragement effects of education subsidies. This implies zero effect on the human capital supply function of these workers (given by equation (2)). In addition, as this policy concerns only workers, the firms' behaviour will not change too and the equilibrium remains invaried. This result suggests that education policies adopted by most of developing and developed countries has no effect on employment rate which can explain the observed persistance of unemployment despite massive public resources devoted to the education sector in these countries.

\section{The impact of subsidizing wage by taxing education}

Under this policy scheme, the government subsidizes the workers' wage paid by firms at a rate of, $\eta$, so that the latter pay a net wage equals to $(1-\eta) w$ instead of $w$. Workers receive the wage paid by the firm plus the amount of the subsidy, $\eta w$, which is transferred to them by government so that they receive, in definitive, the entire wage of $w$.

Total subsidies, $\eta w L$, are financed through a proportional tax, $\tau$, levied through taxing education cost. Indeed, we assume that the government taxes education cost paid by individuals at a rate of, $\tau$, so that the latter pay a total cost equals to $(1+\tau) b h$ instead of $b h$. Thus, total taxes equal to $\tau b h$. Hence, under this policy regime, firms pay a lower wage to workers which increases their chance to be employed but, at a cost of more expensive education.

Under this policy regime, the government's budget equilibrium implies that total subsidies on wages should be equal to total taxes on education cost. That is, the following equality should hold at this equilibrium:

$$
\eta w L=\tau b h
$$

Hence,

$$
\tau=\frac{\eta w L}{b h}
$$

In presence of a wage subsidy, the expected gain function of a representative worker (equation 1b) becomes now:

$$
G=L\left(a h^{\varepsilon}\right)(1-\eta)-b h
$$

The human capital supply function (2) rewrites:

$$
h=\left[\frac{\varepsilon a L(1-\eta)}{b}\right]^{\frac{1}{1-\varepsilon}}
$$


Equation (4) describing the representative firm's profit reads now as follows:

$$
\Pi_{i}=Y_{i}-(1-\eta)\left(a h^{\varepsilon}\right) L_{i}-\sum_{j=1}^{T} p^{X_{j}} X_{i j}
$$

The equation of employment rate (8) rewrites now:

$$
L=\frac{\beta Y}{(1-\eta) a h^{\varepsilon}}
$$

The equation (10) becomes:

$$
L=\left(\frac{\beta A T}{a(1-\eta)}\right)^{\frac{1}{1-\beta}} h^{\frac{\beta-\varepsilon}{1-\beta}} X
$$

Accordingly, the new system $\left(S 1^{*}\right)$ writes as follows:

$$
\left\{\begin{array}{l}
X^{*}=\frac{\gamma \theta}{1-\gamma} \\
L^{*}=\Omega\left(\frac{b}{\varepsilon a(1-\eta)}\right) \frac{1}{2-\varepsilon} \\
h^{*}=\Omega^{\frac{1}{(1-\varepsilon)}}\left(\frac{\varepsilon a(1-\eta}{b}\right)^{\frac{1}{(2-\varepsilon)}} \\
T^{*}=\Omega^{\frac{(1-\gamma)(1-\varepsilon)-\gamma}{(1-\varepsilon)}}\left(\frac{(1-\gamma)}{\gamma C e}\right)^{\gamma} \frac{a(1-\eta)}{A(1-\gamma)}\left(\frac{b}{\varepsilon a(1-\eta)}\right)^{\frac{(1-\varepsilon)}{(2-\varepsilon)}} \\
\text { where: } \Omega=\left(\frac{\gamma \theta}{(1-\gamma)}\right)^{\frac{1-\varepsilon}{2-\varepsilon}}\left(A \gamma^{2}\right)^{-\frac{1-\varepsilon}{(2-\varepsilon)(1-\gamma)}}>0
\end{array}\right.
$$

Implementing a wage subsidy, $\eta$, while taxing education has both a direct and indirect profit effects on the equilibrium employment rate. These effects can be understood by referring to the firm's profit equation above (equation 16).

- The direct effect: the wage subsidy, $\eta$, alleviates the cost of labour, and raises firms' profit, which encourages them to increase their demand for labour (Eq. 17a).

- The indirect effect (via human capital): the wage subsidy influences the level of human capital investment, which in turn, affects firms' profit and therefore their demand for labour. More precisely, this subsidy policy has two opposit effects on $h$ (Eq.15): a discouragement effect associated with taxation which reduces the individual's expected gain $G$; and an encouragement effect stemming from the increased chance to be employed (i.e, an increased employment rate $L$ ) which raises $G$. In order to study the net impact of this policy on the equilibrium, we calculate the derivatives of endogenous variables with respect to $\eta$. By referring to $\left(S 1^{*}\right)$, we can show that: 


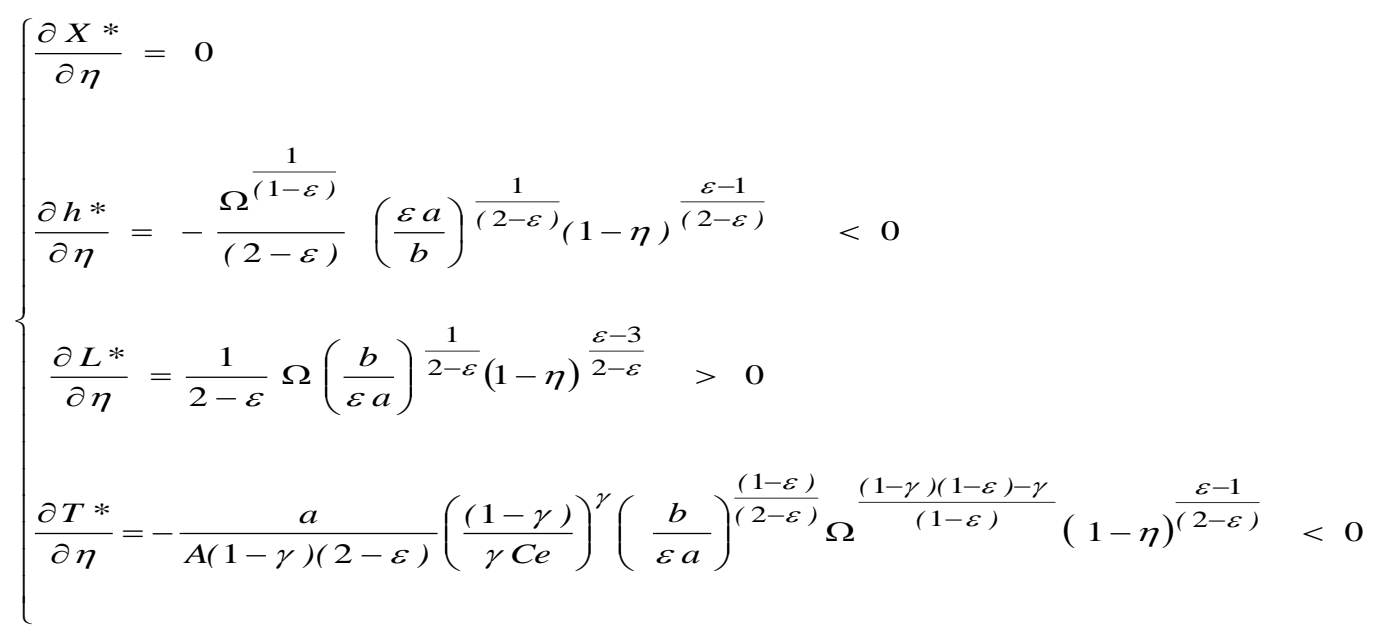

The increase in the wage subsidy, $\eta$, (by increasing education tax, $\tau$ ) reduces, at the equilibrium, workers' human capital and thus increases the employment rate. Hence, from human capital side, this result implies that the negative distortion tax effect outweighs the positive encouragement effect, so that human capital investment declines $\left(\partial h^{*} / \partial \eta<0\right)$. In turn, from firms' side, this decline in human capital together with the encouragement effect of the wage subsidy result in higher employment rate $(\partial L * / \partial \eta>0)$.

\section{Conclusion}

By taking into consideration the mutual interactions in strategic decisions of firms in demanding labour and workers in investing in human capital, we find the following results.

First, there is a negative relationship between education and employment, which can justifiy the persistance of unemployment in most of developped and developping countries despite the increased human capital investment. This result can be seen as complementary to Ho and Tan (2008) which suggests the existence of a non-monotonic relationship between human capital and unemployment. That is, there is a threshold beyond which the impact of number of years of schooling on the probability of unemployment decreases.

Second, subsidizing education through taxing wage -a policy adopted in most of countries- has no effect on employment rate because the negative discouragement effect of tax offsets the positive encouragement effect of education subsidies. This result can explain the observed persistance of unemployment despite massive public resources devoted to the education sector in these countries.

Finally, to reduce unemployment rate, wage should be subsidized and education should be taxed rather than subsidized. This result confirms the one of Charlot and Decreuse (2005)who show that workers consider their private gains from schooling, but not the impact of their decisions on job creation in each sector. The private return to education therefore exceeds the social one, and the optimal policy is to set a tax on education. In addition, Charlot and Decreuse (2010) found that the optimal education policy is to set a tax on education to deter too low ability agents from schooling.

It goes without saying that both our framework and Charlot and Decreuse's ones are parsimonious and leaves much of the real world out. There are, of course, a large number of reasons why subsidizing education. Under borrowing constraints, high-ability individuals from poor families may underinvest in education, and the society could find it beneficial to grant a subsidy to these students. Finally, it is often emphasized that human capital externalities raise output at the aggregate level, and for this reason, the social return to education may exceed the private one. Incorporating these features into our framework is on our research agenda.

\section{References}

[1] Acemoglu, D.T.,(1999) "Changes in unemployment and wage inequality: an alternative theory and some evidence". American Economic Review 89, 1259-1278.

[2] Becker, G. S., (1964), "Human capital: a theoretical and empirical analysis with special references to education", Columbia University Press.

[3] Berman, E. And Machin, S. (2000) "Skilled-biased technology transfer around the world", Oxford review of Economic Policy, 16(3), 12-22

[4] Brunello, G., Garibaldi, P. and E. Wasmer. (2009) "Education and Training in Europe”. Oxford University Press.

[5] Burdett, K., Smith, E., (2002). "The low skill trap". European Economic Review 46,1439-1451

[6] Charlot, O.and Decreuse, B., (2005) "Self-selection in education with matching frictions". Labour Economics 12, $251-267$.

[7] Charlot, O., (2005), "Education et chômage dans les modèles d'appariement: une revue de literature", Economie et Prévision, 2005/3-4-5, $\mathrm{n}^{\circ}: 169,73-103$. 
[8] Charlot, O. And Decreuse, B (2010) "Over-education for the rich, under-education for the poor: A search-theoretic microfoundation" Labour Economics 17 (2010) 886-896

[9] Devine, Theresa and Kiefer, Nickolas M. (1991) "Empirical Labour Economics. The Search Approach" Oxford University Press

[10] Farber, Henry S. (2004). "Job Loss in the United States, 1981 to 2001." Research in LaborEconomics 23: 69-117.

[11] Garrouste,C.; Kozovska,K. and Perez,E,A. (2010) “Education and Long-Term Unemployment” European Commission ,Joint Research Centre working paper EUR 24450.

[12] Givord, P. and Maurin, E (2003) «La montée de l'instabilité professionnelle et ses causes » Revue économique Vol. 54, N 3 , pages 617 à 626

[13] Higashi, Y., (2002), "Firm specific human capital and unemployment in a growing economy", Japan and the World Economy, 14, $35-44$.

[14] Ho, K. And R. Tan (2008) "Nonmonotonic relationship between human capital and unemployment: an exploratory study with empirical evidence on Signapore." Applied Economics Letters, 15: 1177-1185.

[15] Kettunen, J. (1994) "The effects of education on the duration of unemployment." Labour, 8: 331-352.

[16] Kadzamira E.C. (2003). “ Where Has All The Education Gone In Malawi?',Institute of Development Studies at the University of Sussex. Brighton BN1 9RE, UK

[17] Laing, D., Palivos, T., Wang, P., (1995). “Learning, matching and growth”. Review of Economic Studies 62, 115-129.

[18] Machin, S. and A. Manning (1999). "The causes and consequences of long-term unemployment in Europe." Handbook of Labour Economics, 3(3): 3085-3139.

[19] McIntosh, Steven (2008) "Education and employment in OECD countries" UNESCO: International institue for educational planning.

[20] Mincer, J., (1974), "Schooling, experience and earnings", New York: Columbia University Press.

[21] MINCER J. [1991], "Education and unemployment", NBER Working Paper n 3838

[22] Mincer, J. (1994) "Human Capital: A Review." In Clark Kerr et al. (eds) Labour economic and Industrial Relations: Markets and Institutions. Cambridge: Harvard University Press.

[23] Moen, E.R., (1999) "Education, ranking, and competition for jobs". Journal of Labor Economics 17, 694-723.

[24] Nickell, Stephen. (1979). "Estimating the Probability of Leaving Unemployment.” Econometrica 47: 1249-1266.

[25] Pfeiffer D. and G. Chiunda (2008). “Tracer Study of TEVETE and Higher Education Completers in Malawi”, Final Report', mimeo

[26] Psacharopoulos, G., (1994), "Returns to investment in education: A global update", World Development 22, 9, $1325-43$.

[27] Psacharopoulos, G., and Patrinos, H.A.,(2004), "Returns to investment in education: A further update", Education Economics, 12, 2, 111-134

[28] Pissarides,C.A.,(1990),"Equilibrium unemployment theory”, Oxford, Brasil Blackwell.

[29] Riddell, W. Craig and Song, X. (2011) "The Impact of Education on Unemployment Incidence and Re-employment Success: Evidence from the U.S. Labour Market". Discussion Paper No. 5572

[30] Romer, P. M., (1990), "Endogenous technical change", Journal of Political Economy, 98, 71-102.

[31] Spence, M. (1981) "Signaling, screening, and information.” In Rose, S. (ed) Studies in Labour Markets. Chicago: University of Chicago Press.

[32] Winkelmann, R. (1996) "Employment prospects and skills acquisition of apprenticeshiptrained workers in Germany." Industrial and Labour Relations Review, 49: 658-672. 